\title{
A Further Observation of Multiaxonal Nerve Endings Innervating Intrafusal Muscle Fibers of the Chinese Hamster*
}

\author{
Junzo Desaki and Yasuo Uehara \\ Department of Anatomy, Ehime University School of Medicine, Shigenobu, Ehime, Japan
}

Received June 6, 1988

\begin{abstract}
Summary. In addition to annulospiral sensory endings and fusimotor endings, multiaxonal nerve endings consisting of a bundle of naked axons were frequently found in the muscle spindles of the adult Chinese hamster. The multiaxonal endings were mainly distributed in the equatorial region of the nuclear bag fibers, adjacent to the annulospiral sensory endings. Terminal axons composing the endings were less than $1.5 \mu \mathrm{m}$ in diameter and contained a significant number of clear synaptic vesicles and large granulated vesicles. Some axons formed synaptic contacts with each other and with the muscle cell surface. These structural features suggest that the multiaxonal endings are efferent in nature. They may possibly represent a temporal structure of fusimotor endings, or belong to the autonomic nerves.
\end{abstract}

One of the authors has previously reported the occurrence of a particular type of ending innervating intrafusal muscle fibers of the muscle spindle in the young adult rat (UEHARA, 1973). This consisted of a bundle of naked axons which contained an aggregation of mitochondria and were distributed in the juxtaequatorial region, adjacent to the annulospiral sensory endings. They directly contacted the intrafusal fiber surface without an intervening basal lamina. From these structural features, the endings were judged to be sensory in nature, retaining embryonal features of the annulospiral endings in the adult life. This multiaxonal configuration is common to maturing peripheral nerve fibers and endings (REDFERN, 1970 ; KORNELIUSSEN and JANSEN, 1976; BROWN et al., 1976; ZELENA et al., 1979; BIXBY, 1981; RILEy, 1981).

During a systematic survey of muscle spindles in various mammalian species, we found the multiaxon- al endings to occur with significantly high frequency in the muscle spindles of fully matured Chinese hamsters. The present study describes the structural organization of the endings in finer detail. These data shall hopefully facilitate our understanding of the stretch receptor mechanism. As is generally admitted, muscle spindles are, next to the eyes and ears, the most complex receptor organ both in structure and innervation pattern.

\section{MATERIALS AND METHODS}

The tenuissimus muscle of 3-month-old Chinese hamsters (Cricetulus griseus) weighing 40-50 g was used. After the animals were anaesthetized with ether, the muscle was dissected out and cut into several segments about $2 \mathrm{~mm}$ long. The procedure for electron microscopy was the same as described elsewhere (DESAKI and Uehara, 1983). Fifty muscle spindles were obtained from different animal sources and were examined with a Hitachi HU 12A electron microscope.

\section{RESULTS}

Annulospiral sensory endings were consistently found in the muscle spindles of the tenuissimus muscle of the Chinese hamster along the equatorial to the juxtaequatorial region. They exhibited, in cross sections of the spindle, a semilunar or horseshoe-shaped profile around the perimeter of intrafusal muscle fibers. They were devoid of associated Schwann cell investment and characteristically contained an aggregation

\footnotetext{
*This work was partly supported by a grant from the Ministry of Education, Science and Culture, Japan
} 
of mitochondria.

The multiaxonal endings were encountered at the equatorial region adjacent to the annulospiral endings, occurring in 5 instances out of 50 muscle spindles examined. They were often found to coexist with the annulospiral endings along the same plane of the sections, being mostly associated with the nuclear bag fibers and rarely with the nuclear chain fibers (Fig. 1). They consisted of a bundle of less than 20 terminal axons $0.1-1.5 \mu \mathrm{m}$ in diameter which were closely apposed to each other with a narrow interstice of less than $20 \mathrm{~nm}$. Schwann cell processes did not appear to be involved in the bundle formation (Fig. 2). They either lay on the surface of the intrafusal fibers in shallow grooves or deeply penetrated the sarcoplasm as the annulospiral endings occasionally are reported to do so (GRUNER, 1961). The gap between the terminal axons and the muscle surface was less than $20 \mathrm{~nm}$ in width and contained no interposing basal lamina. The disposition of the multiaxonal endings appeared rather irregular, being neither circular nor parallel with respect to the long axis of the muscle fiber. The terminal axons contained a number of small spherical clear vesicles which were rather consistent in size, ranging from 40 to $70 \mathrm{~nm}$, about $50 \mathrm{~nm}$ on average. They also contained large granular vesicles $80-$ $130 \mathrm{~nm}$ in diameter.

Along the axon-muscle contact area were what appeared to be synapses, consisting of a focal accumulation of electron dense materials to which clear vesicles converged (Fig. 3). Similar but more discrete synaptic contacts with postsynaptic specialization were frequently encountered between adjacent terminal axons (Fig. 4). In addition, desmosome-like specializations were occasionally found along the general contact area of the adjacent axons (Fig. 5) and along the nerve-muscle apposition (Fig. 6). The stem nerves from which multiaxonal endings originated also consisted of a bundle of naked axons (Fig. 7).
Again, no Schwann cell processes appeared to be present in the bundle. Instead, a part of the outermost axons were closely associated with fibroblast-like cell processes which lacked a basal lamina. The stem nerves appeared to run longitudinally to the axis of the intrafusal muscle fibers along the inner capsule cell, covering if for a long distance and then contacting the fibers near the end of the sensory endings (Fig. 8).

\section{DISCUSSION}

The present study indicated that multiaxonal endings were rare structures but did occur, with significant frequency, in the muscle spindles of the adult Chinese hamster. They were, in fact, found in $10 \%$ of the spindles examined. The endings basically resembled the bundled endings reported once-in a muscle spindle of the young adult rat-as being sensory in nature (UEHARA, 1973), but differed in that they contained a number of clear vesicles which corresponded in size to synaptic vesicles, and in that the terminal axons formed what appeared to be synaptic contacts to each other and to the intrafusal muscle fibers. These features may indicate the multiaxonal endings being efferent rather than afferent in nature. If this is the case, two possibilities exist: they simply represent a temporal feature of fusimotor endings or they are autonomic in nature. Apart from their multiaxonal configuration, the endings differed in other ways from fusimotor endings. The fusimotor endings usually keep epilemmal position, i.e., there is a gap containing a basal lamina between axon and muscle plasma membranes. The multiaxonal endings and intrafusal muscle fibers are, on the other hand, separated by only a narrow interstice without intervention of a basal lamina, keeping a hypolemmal position.

The multiaxonal endings have not been associated

Fig. 1. Equatorial region of a muscle spindle of the adult Chinese hamster, showing two kinds of nerve endings; annulospiral sensory endings $(A n)$ innervating a nuclear chain fiber $(N c 1)$ and nuclear bag fiber $(N b 1)$, and multiaxonal ending $(\mathrm{Ma})$ innervating a nuclear bag fiber $(\mathrm{Nb2}) . \mathrm{Nc2}$ nuclear chain fiber, $\mathrm{Ic}$ inner capsule. $\times 6,400$

Fig. 2. Multiaxonal endings $(M a)$ penetrating deeply into a nuclear bag fiber $(N b)$. Note the significant number of clear vesicles and large granulated vesicles in the terminal axons. $A n$ annulospiral sensory ending. $\times 18,000$

Fig. 3. A synaptic contact between a terminal axon and muscle cell (arrow). Note the converged synaptic vesicles at the presynaptic site and no definite postsynaptic accumulation of electron dense material. $\times 46,000$

Fig. 4. A synaptic contact between two terminal axons (arrow). Note the focal conversion of synaptic vesicles at the presynaptic site and an accumulation of electron dense material at the postsynaptic site. $\times 31,000$

Fig. 5. A desmosome-like structure between two terminal axons (arrow). $\times 52,000$

Fig. 6. Desmosome-like structures between a terminal axon and muscle cell (arrows). $\times 37,000$ 

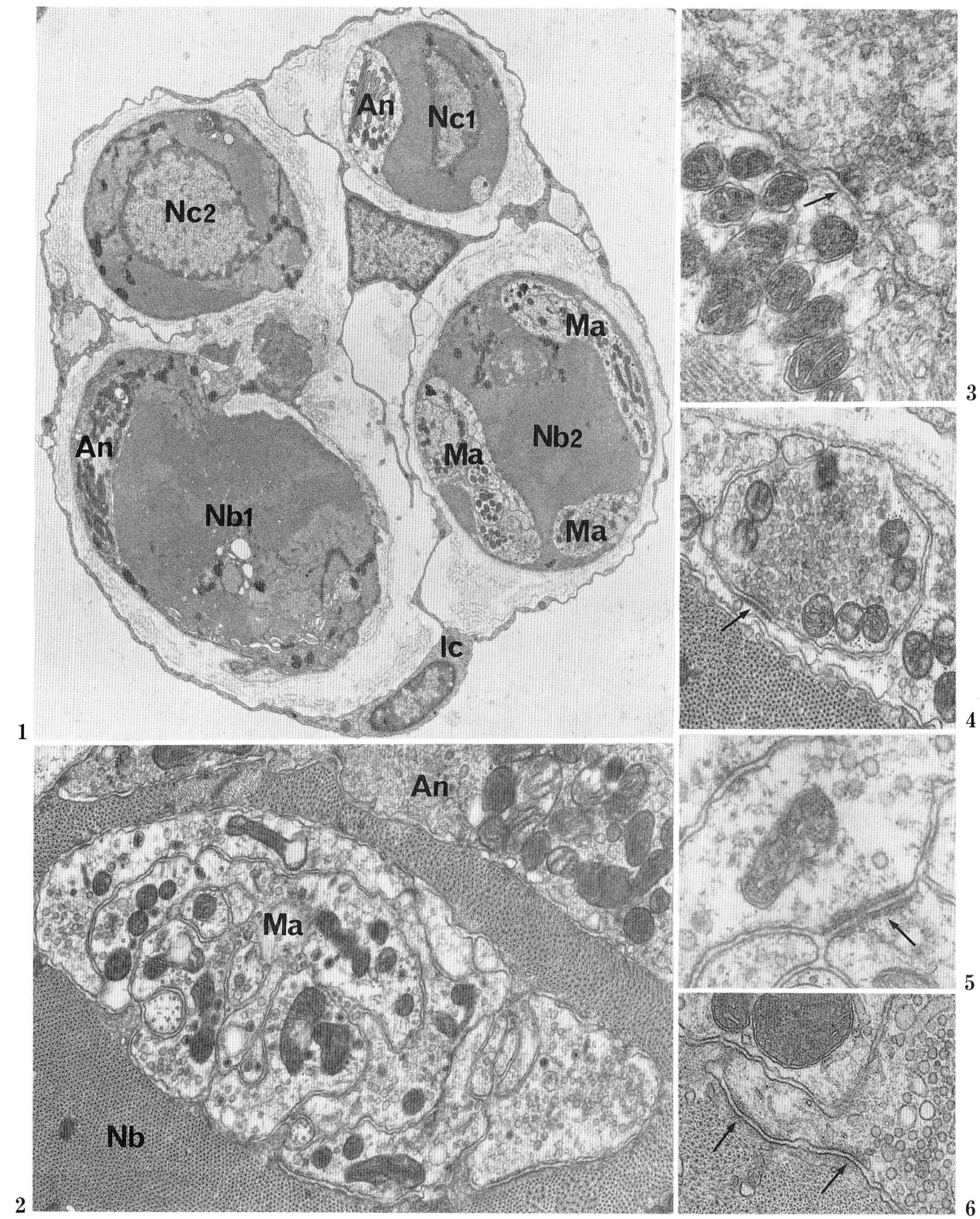

Figs. 1-6. Legends on the opposite page. 


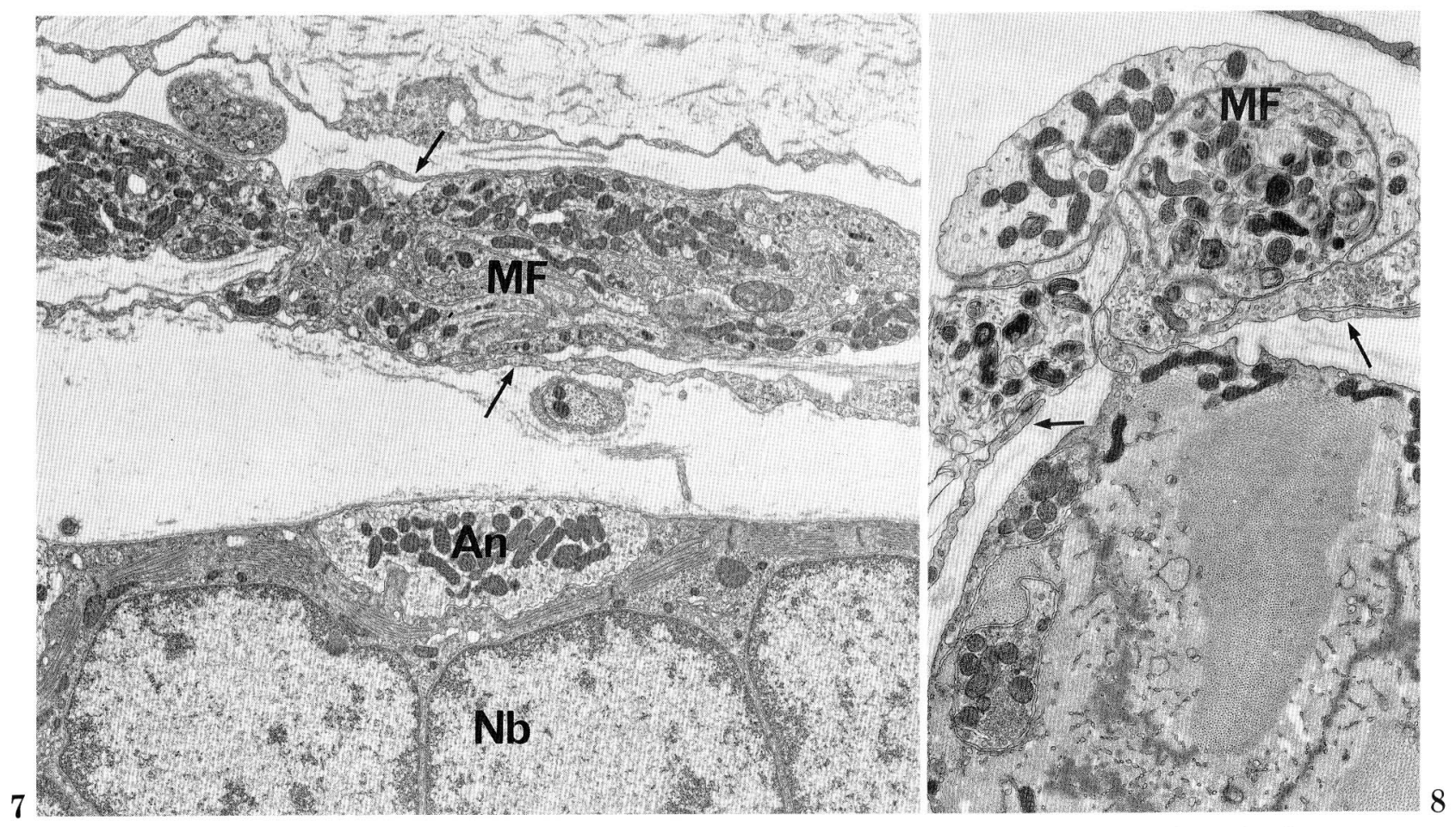

Fig. 7. Longitudinal section of the stem nerves $(M F)$ of the multiaxonal ending running along the inner capsules (arrows) in the equatorial region. The stem nerves also consist of a bundle of naked axons. $N b$ nuclear bag fiber, $A n$ annulospiral sensory ending. $\times 8,100$

Fig. 8. Initial portion of multiaxonal stem nerves $(M F)$ contacting the nuclear bag fiber near the end of the annulospiral sensory ending. Arrows indicate the inner capsule. $\times 10,000$

with Schwann cell processes, whereas the fusimotor endings are invested by a Schwann cell covering at their nonsynaptic perimeter. Furthermore, the fusimotor endings are derived from myelinated nerve fibers, whereas the multiaxonal endings appear to be originated from a nonmyelinated stem fiber. Nevertheless, some evidence supports the view that the multiaxonal endings do represent some temporary features of the fusimotor endings. BARKER and IP (1966) proposed a replacement hypothesis where new fusimotor endings might occasionally be formed by collateral and ultraterminal growing sprouts from the myelinated stem nerve fiber. The growing sprouts thus formed are apparently nonmyelinated. LANDON (1972) has shown that the developing fusimotor endings often take the form of multiple end bulbs consisting of a number of axons that are incompletely separated from each other by Schwann cell processes. Another possibility is that the multiaxonal endings are autonomic in nature. The sympathetic innervation of intrafusal muscle fibers has been suggested to occur in dog and cat muscle spindles, with histo- chemistry for catecholamines and also by using 5-hydroxydopamine (BANKER and GIRVIN, 1971; SANTINI and IBATA, 1971; BARKER and SAITO, 1981). Terminal varicosities containing small and large granular vesicles which were considered to be postganglionic sympathetic noradrenergic endings were also reported to occur near the nuclear chain fiber in the juxtaequatorial region in the cat (BALLARD, 1978). We are currently testing these two possibilities by applying histochemical analysis and a denervation experiment.

\section{REFERENCES}

BALLARD, K. J.: Typical sympathetic noradrenergic endings in a muscle spindle of the cat. J. Physiol. (Lond.) 285: 61-62P (1978).

Banker, B. Q. and J. P. Girvin: The ultrastrutural features of the mammalian muscle spindle. J. Neuropathol. Exp. Neurol. 30: 155-195 (1971). 
BARKER, D. and M. C. IP: Sprouting and denervation of mammalian motor axons in normal and de-afferentated skeletal muscle. Proc. Roy. Soc. B 163: 538-554 (1966).

BARKER, D. and M. SAITo: Autonomic innervation of receptors and muscle fibres in cat skeletal muscle. Proc. Roy. Soc. Lond. B 212: 317-332 (1981).

BIXBY, J. L.: Ultrastructural observations on synapse elimination in neonatal rabbit skeletal muscle. J. Neurocytol. 10: 81-100 (1981).

Brown, M. C., J. K. S. JANSEN and D. VAN Essen: Polyneuronal innervation of skeletal muscle in newborn rats and its elimination during maturation. J. Physiol. 261: 387-422 (1976).

DeSAKI, J. and Y. UEHARA: A fine-structural study of the termination of intrafusal muscle fibres in the Chinese hamster. Cell Tiss. Res. 234: 723-733 (1983).

GRUNER, J. E.: La structure fine du fuseau neuromusculaire humain. Rev. Neurol. 104: 490-507 (1961).

KoRneliussen, H. and J. K. JANSEN : Morphological aspects of the elimination of polyneuronal innervation of skeletal muscle fibres in newborn rats. J. Neurocytol. 5: 591-604 (1976).

LANDon, D. N.: The fine structure of the equatorial regions of developing muscle spindles in the rat. J. Neurocytol. 1: 189-210 (1972).

REDFERN, P. A.: Neuromuscular transmission in newborn rats. J. Physiol. 209: 701-709 (1970).
RiLeY, D. A.: Ultrastructural evidence for axon retraction during the spontaneous elimination of polyneuronal innervation of the rat soleus muscle. J. Neurocytol. 10: 425-440 (1981).

SAntini, M. and Y. Iвata: The fine structure of thin unmyelinated axons within muscle spindles. Brain Res. 33: 289-302 (1971).

UEHARA, Y.: Unique sensory endings in rat muscle spindles. Z. Zellforsch. 136: 511-520 (1973).

Zelena. J., F. Vyskocil and I. JiRManova: The elimination of polyneuronal innervation of end-plates in developing rat muscle with altered function. Prog. Brain. Res. 49: 365-372 (1979).

Dr. Junzo DESAKI

Department of Anatomy

Ehime University School of Medicine Shigenobu, Ehime

791-02 Japan

出崎順三 791-02 愛媛県温泉郡重信町志津川 愛媛大学医学部 第二解剖学教室 